\title{
Second Report of the Cooperative, Open-Ended Study of Slowly Growing Mycobacteria by the International Working Group on Mycobacterial Taxonomy
}

L. G. WAYNE, ${ }^{1 *}$ R. C. GOOD, ${ }^{2}$ M. I. KRICHEVSKY, ${ }^{3}$ R. E. BEAM, ${ }^{2}$ Z. BLACKLOCK, ${ }^{4}$ H. L. DAVID, ${ }^{5}$ D. DAWSON, ${ }^{4}$ W. GROSS, ${ }^{6}$ J. HAWKINS, ${ }^{6}$ P. A. JENKINS, ${ }^{7}$ I. JUHLIN, ${ }^{8}$ W. KÄPPLER, ${ }^{9}$ H. H. KLEEBERG, ${ }^{10}$ I. KRASNOW, $M$. J. LEFFORD, ${ }^{11}$ E. MANKIEWICZ, ${ }^{12}$ C. MCDURMONT, ${ }^{13}$ E. E. NEL, ${ }^{10}$ F. PORTAELS, ${ }^{14}$ P. A. RICHARDS, ${ }^{1}$ S. RÜSCH,${ }^{15} \mathrm{~K}$. H. SCHRÖDER, ${ }^{15} \mathrm{~V}$. A. SILCOX, ${ }^{2} \mathrm{I}$. SZABO, ${ }^{16} \mathrm{M}$. TSUKAMURA, ${ }^{17}$ L. VANDEN BREEN,${ }^{14}$ AND B. VERGMANN ${ }^{18}$

Veterans Administration Medical Center, Long Beach, California $90822^{1}$; Centers for Disease Control, Atlanta, Georgia 303332; National Institute of Dental Research, Bethesda, Maryland 20205 ${ }^{3}$; State Health Laboratory, Brisbane, Australia ${ }^{4}$; Institut Pasteur, Paris, France ; Veterans Administration Hospital, West Haven, Connecticut 06516 ${ }^{6}$; University Hospital of Wales, Cardiff, Wales ${ }^{7}$; Institute of Clinical Bacteriology, Malmö, Sweden ; Forschunginstitut für LungenKrankheiten and Tuberkulose, Berlin-Buch, German Democratic Republic ; Tuberculosis Research Institute, Medical Research Council, Pretoria 0001, South Africa ${ }^{10}$; Wayne State University, Detroit, Michigan $48201^{11}$; Lakeshore General Hospital, Pointe Claire, Quebec, Canada ${ }^{12}$; State Department of Public Health, Montgomery, Alabama $36130^{13}$; University of Antwerp and Institute of Tropical Medicine, Antwerp, Belgium ${ }^{14} ;$ Tuberkulose-Forschunginstitut, Borstel, German Federal Republic ${ }^{15}$; Koranyi National Institute of Tuberculosis and Pulmonology, Budapest, Hungary ${ }^{16}$; Chubu Chest Hospital, Obu, Aichi-Ken, Japan ${ }^{17}$; and Statens Seruminstitut, Copenhagen, Denmark $^{18}$

The open-ended study of the International Working Group on Mycobacterial Taxonomy is an ongoing project designed to characterize slowly growing strains of mycobacteria that do not belong to well-established or thoroughly characterized species. In this second report, we describe Mycobacterium malmoense and some members of the "MAIS intermediate" group, as well as make minor adjustments of the feature frequency data for Mycobacterium simiae and Mycobacterium szulgai.

The earliest cooperative studies of the International Working Group on Mycobacterial Taxonomy were designed to apply modern taxonomic methods to the circumscription and description of most recognized species of mycobacteria $(2,5,7,9,16,17)$. These studies were based on a permissive philosophy, wherein participants were free to choose their own tests and methods of performance. Later, additional studies were undertaken, in which participants agreed to follow precisely defined protocols for selected tests in order to evaluate the intra- and inter-laboratory reproducibility of those features that had exhibited the greatest differential power in the permissive studies $(18,19)$.

In 1977, a cooperative open-ended study was undertaken by the International Working Group on Mycobacterial Taxonomy to examine slowly growing mycobacterial strains which represented uncommonly encountered species that had not been represented in the earlier studies, as well as strains that did not conform to any of the recognized slowly growing species. In the first report of that continuing project (20), expanded descriptions of Mycobacterium szulgai, Mycobacterium simiae, and Mycobacterium shimoi- dei were presented. $M$. shimoidei was without standing at the time, but has since been revived (13). A very limited description of Mycobacterium asiaticum was also provided, and some evidence was presented for reconsideration of the former species "Mycobacterium paraffinicum" (1), which was without standing.

In this second report of the open-ended study of slowly growing mycobacteria, we present an expanded description of Mycobacterium malmoense Schröder and Juhlin 1977 (10), as well as some adjusted figures for the feature frequencies of $M$. simiae and $M$. szulgai. In addition, we include information on some strains that conform to the criteria for the "MAIS intermediate" group of Hawkins (3), although resolution of the taxonomic status of these strains is not yet possible.

\section{MATERIALS AND METHODS}

Selection of strains. The criteria for and mechanics of introduction of cultures into this study have been described previously (20). The strains used in this study are divided into two categories on the basis of the mode of acquisition of data for analysis. "New strains" are those that were acquired specifically for 
this open-ended study, and these cultures (designated by strain numbers above 90,000 ) were distributed to all participants in the study. "Old strains" are those that were examined in previous International Working Group on Mycobacterial Taxonomy cooperative studies $(7,16,17)$, and these strains, bearing American Type Culture Collection (ATCC) numbers below 30,000 , were not reexamined by the participants in the open-ended study. Instead, data from the previous studies were added to the data bank for the new study. A total of 14 of the old strains (including 4 type strains) were selected to serve as marker strains for species or clusters recognized in the previous studies; the remaining 24 old strains were selected because they previously did not fall into any well-defined cluster. As noted previously (20), after the data for the openended project were edited, an average of only 38 features were available for the old strains, compared with 92 features for the new strains. The consequences of this imbalance have been discussed previously (20), and both an analysis of the composite data and an analysis of the data for the new strains alone are presented below.

Editing and analysis of data. The data were edited by using criteria discussed previously $(14,20)$. Numerical taxonomy (NT) analyses were based on simple match- ing coefficients, with sorting by unweighted average linkage $(12,15)$, and a table of feature frequencies was generated for selected clusters (15).

As reported previously (20), the combination of data for the old strains, with an average of only 38 features, with data for the new strains, with an average of 92 features, produced marked perturbations of the NT analyses. These perturbations were reflected in the relative frequencies of intercluster strain pair crossovers at matching scores (M scores) equal to or greater than $\mathbf{8 0 \%}$. Although old strains accounted for $54 \%$ of the strains in the previous study (20), $66 \%$ of the crossovers at $\mathrm{M}$ scores of $\geq 80 \%$ were between two old strains, $25 \%$ were between an old strain and a new strain, and only $9 \%$ involved two new strains. Therefore, separate NT analyses were performed with the combined data derived from old and new strains and with the data derived from new strains alone. The composite dendrogram (Fig. 1) and a composite triangular matrix

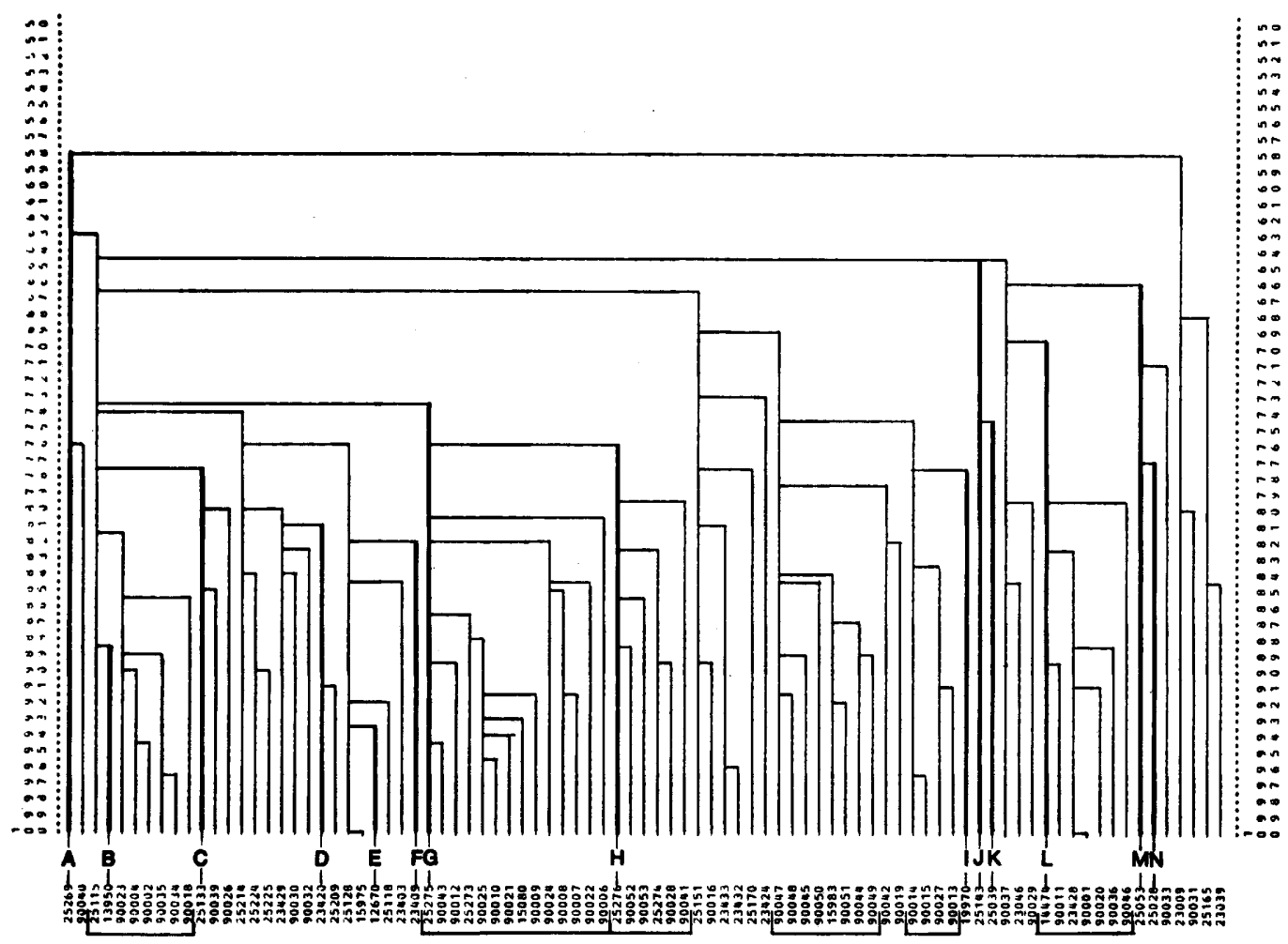

FIG. 1. Composite dendrogram of old and new strains. The vertical scale indicates $M$ scores (percent). The letters identify marker strains, as follows: A, M. terrae; B, M. intracellulare; C, M. avium; D, M. scrofulaceum; E, "M. paraffinicum" ; F, M. gordonae; G, M. simiae; H, M. asiaticum; I, M. xenopi; J, M. nonchromogenicum; K, M. marinum; L, M. flavescens; M, M. kansasii; N, M. gastri. The brackets at the bottom were added to assist in visualizing the relationships of clusters to the nearest known marker strains. The analysis of old strains (strain numbers below 90,000 ) was based on an average of 38 features per strain, and the analysis of new strains (strain numbers above 90,000 ) was based on an average of 92 features per strain. 
(data not shown) were useful for locating the marker strains in clusters that included new strains and for calculating mean $M$ scores for the marker strains compared with the new strains in each cluster (Table 1). The triangular NT matrix resulting from the analysis that was limited to the new strains is shown in Fig. 2, and the calculated mean intra- and intercluster $M$ scores for the well-defined clusters in this set are given in Table 2.

It should be noted that the dendrogram (Fig. 1) shows only average linkage relationships, whereas the triangular matrix (Fig. 2), which was also based on average linkage, permits symbolic representation of individual strain pair $M$ scores as well. This difference in formats, together with the perturbations introduced into the average linkage scores in Fig. 1 by the inclusion of old strains, accounts for the apparent differences in sequential and numerical relationships of some strain pairs expressed in Fig. 1 and 2.

The selected feature frequencies for each of the well-defined clusters (Table 3) are based solely on new strains. These frequencies may differ slightly from those given in the first report (20), which was based on the composite data, but the descriptions of the taxa are not significantly changed.

The results of thin-layer chromatography (TLC) of bacillary lipids and agglutination serotyping were not included in the NT analysis, but are presented independently, by clusters, in
Table 4. Colonial morphology and phage typing were excluded from this analysis, since prior examination (20) had yielded little inter-laboratory reproducibility.

Six of the marker strains identified in the composite dendrogram (Fig. 1), strains A (Mycobacterium terrae ATCC 25269), I (Mycobacterium xenopi ATCC 19970) J (Mycobacterium nonchromogenicum ATCC 25143), K (Mycobacterium marinum ATCC 25039), M (Mycobacterium kansasii ATCC 25053), and N (Mycobacterium gastri ATCC 25028), were not linked to any cluster on the dendrogram at an $\mathbf{M}$ score greater than $77.5 \%$ or to any cluster on the restricted NT matrix (Fig. 2) at a mean M score greater than $78.9 \%$ (Table 1).

Hawkins (3) has proposed a temporary category for ill-defined slowly growing strains called the MAIS intermediate group. These strains are characterized by negative reactions in the tests for hydrolysis of Tween 80 and reduction of nitrate and by combinations of colony pigmentation and reactions in the urease and semiquantitative catalase tests that prevent unequivocal placement in either the Mycobacterium aviumMycobacterium intracellulare complex or the species Mycobacterium scrofulaceum. It is evident that some of the strains that meet these criteria can be accommodated in the species $M$. simiae, which may be quite variable in pigment production (20). However, the appearance of the separate cluster designated MAIS-1 in this study (Fig. 2) indicates that $M$. simiae does not ac-

TABLE 1. Mean $M$ scores of the clusters compared with the marker strains"

\begin{tabular}{|c|c|c|c|c|c|c|c|}
\hline \multirow{2}{*}{$\begin{array}{l}\text { Marker } \\
\text { desig- } \\
\text { nation }\end{array}$} & \multirow[b]{2}{*}{ Strain } & \multicolumn{6}{|c|}{$\begin{array}{c}\text { Mean M score (\%) of marker strains compared with new strains in } \\
\text { cluster: }^{b}\end{array}$} \\
\hline & & $\begin{array}{c}1 \\
(M . \\
\text { simiae })\end{array}$ & $\begin{array}{c}2 \\
(\boldsymbol{M} . \\
\text { asiaticum })\end{array}$ & $\stackrel{3}{\text { (MAIS-1) }}$ & $\begin{array}{c}4 \\
(M . \\
\text { malmoense })\end{array}$ & $\begin{array}{c}5 \\
(M . \\
\text { szulgai })\end{array}$ & $\begin{array}{c}6 \\
(M . \\
\text { shimoidei })\end{array}$ \\
\hline A & M. terrae ATCC 25269 & & 73.2 & & & & \\
\hline $\mathbf{B}$ & $M$. intracellulare ATCC $13950^{\mathrm{T}}$ & & & 82.4 & & & \\
\hline $\mathrm{C}$ & M. avium ATCC 25133 & & & 77.5 & & & \\
\hline D & M. scrofulaceum ATCC 23420 & 78.9 & & 74.1 & 70.5 & & \\
\hline $\mathbf{E}$ & "M. paraffinicum" ATCC 12670 & 81.7 & 80.1 & 78.4 & 72.0 & & \\
\hline$\overline{\mathbf{F}}$ & M. gordonae ATCC 23409 & & 81.6 & & 70.5 & 70.7 & \\
\hline $\mathrm{G}$ & $M$. simiae ATCC $25275^{\mathrm{T}}$ & 85.5 & & 74.0 & & & \\
\hline $\mathbf{H}$ & M. asiaticum ATCC $25276^{\mathrm{T}}$ & 80.7 & 86.3 & 80.9 & & 75.5 & \\
\hline I & M. xenopi ATCC 19970 & & & & 71.0 & & 77.3 \\
\hline $\mathbf{J}$ & M. nonchromogenicum ATCC 25143 & & & & & & \\
\hline $\mathbf{K}$ & $M$. marinum ATCC 25039 & & 72.4 & & & & \\
\hline $\mathbf{L}$ & M. flavescens ATCC $14474^{\mathrm{T}}$ & & & & & 78.0 & \\
\hline $\bar{M}$ & M. kansasii ATCC 25053 & & 73.0 & & & 78.9 & \\
\hline $\mathbf{N}$ & M. gastri ATCC 25028 & & & & & & \\
\hline
\end{tabular}

${ }^{a}$ The marker strains (Fig. 1) are based on old data from previous International Working Group on Mycobacterial Taxonomy cooperative studies, and the clusters (Fig. 2) are based solely on the new strains used in the open-ended study. The mean internal $M$ scores for the new strains of clusters 1 through 6 were 83.1, 79.2, 88.3, 85.5, 85.0, and $86.3 \%$, respectively.

${ }^{b}$ No value indicates an $M$ score of $<70 \%$. 
count for all such strains. Each of the strains in the MAIS-1 cluster exhibited a mean M score below $80 \%$ when compared with members of the $M$. simiae cluster in Fig. 2. The apparent homogeneity of the MAIS-1 cluster and the overall agreement of the features of this cluster (Table 3 ) with those of $M$. intracellulare (20) prompted a detailed examination of the data submitted for the component strains. This analysis revealed that the MAIS-1 cluster is not as clearly defined as it appears from the NT matrix, and thus it is necessary to discuss the strains individually.

Strain 90004 was submitted to the study as a subculture of one of the reference cultures of Schaefer for the "simiae 1" serovar (labeled subculture 44731r). On submission, this strain was recorded as scotochromogenic and urease positive, but after recoding and distribution to participants, it was linked to marker strain B $(M$. intracellulare ATCC $13950^{\mathrm{T}}$ [type strain]) at a level of $86.2 \%$ and the concensus results (including those of the original submitter) indicated negative pigmentation and urease reactions and agglutination as "avium complex" serovar 25.
Some photochromogenicity was reported by 3 of 14 laboratories. Furthermore, strain 90023, which was derived from the same culture and inadvertently entered into the study some time after strain 90004, was also reported to be nonpigmented, urease negative, and a member of serovar 25. It is no longer possible to obtain the original source strain from the submitter, and it is probably appropriate to consider these two strains as $M$. intracellulare strains that entered the study through some error in labeling of the parent culture.

Strain 90002 was selected for inclusion because it appeared to exhibit biochemical behavior that was compatible with $M$. intracellulare, but was derived from one of the reference cultures of Schaefer (culture 84490) of avium complex serovar 18. This serovar was not encountered in the $\boldsymbol{M}$. avium- $\boldsymbol{M}$. intracellulare clusters in a previous International Working Group on Mycobacterial Taxonomy study (7), but it was common in the $M$. simiae cluster that emerged in a later study (20). Strain 90002 was linked to strain 90004 at an $M$ score of $94.3 \%$, to $M$.

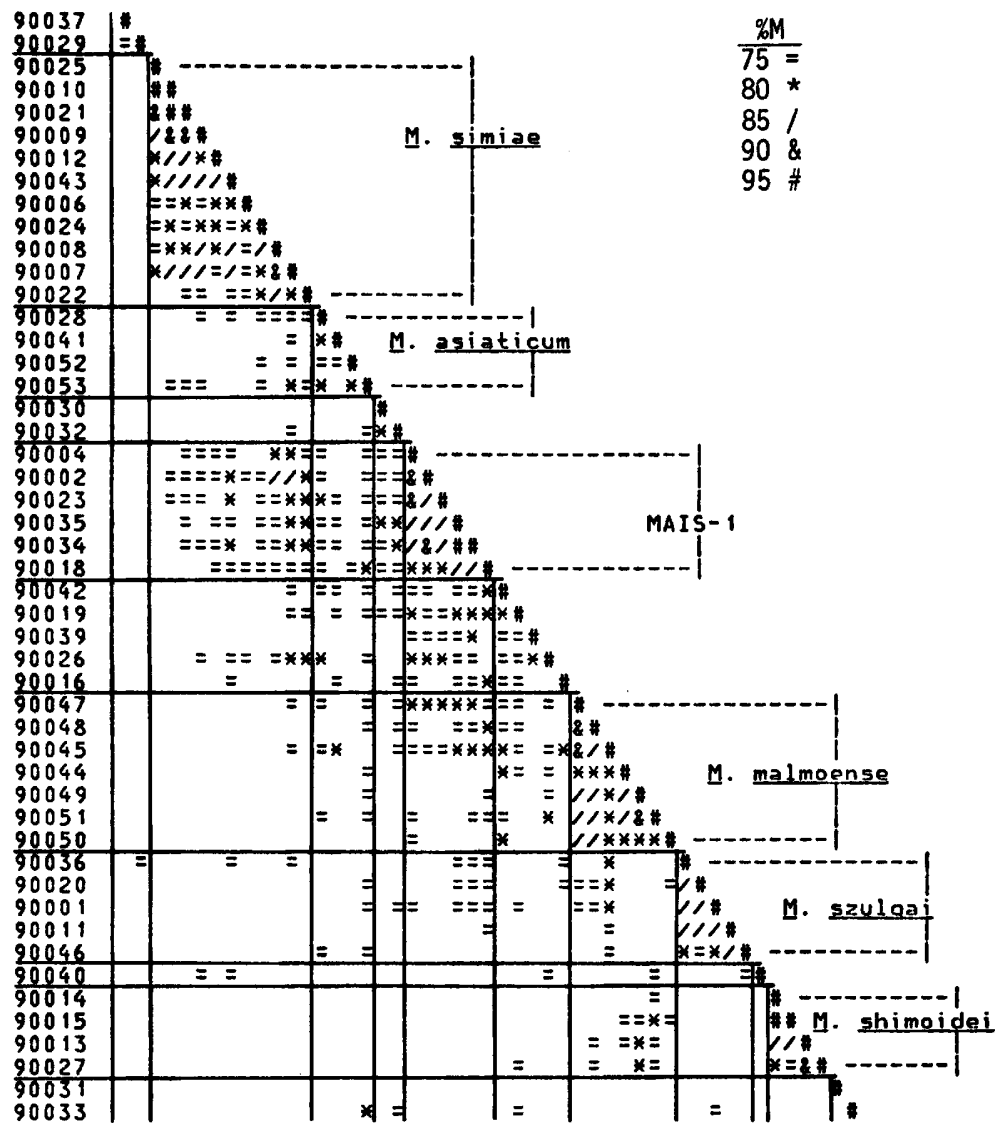

FIG. 2. NT triangle matrix restricted to new strains. 
TABLE 2. Mean intra- and intercluster $M$ scores of new strains in the restricted NT triangle matrix ${ }^{a}$

\begin{tabular}{|c|c|c|c|c|c|c|c|c|}
\hline \multicolumn{2}{|c|}{ Cluster } & \multirow{2}{*}{$\begin{array}{l}\text { No. of } \\
\text { strains }\end{array}$} & \multicolumn{6}{|c|}{ Mean M score $(\%)$ of cluster: } \\
\hline $\begin{array}{l}\text { Desig- } \\
\text { nation }\end{array}$ & Taxon & & 1 & 2 & 3 & 4 & 5 & 6 \\
\hline 1 & M. simiae & 11 & $(83.1)$ & & & & & \\
\hline 2 & M. asiaticum & 4 & 73.6 & $(79.2)$ & & & & \\
\hline 3 & MAIS-1 & 6 & 76.9 & 76.1 & $(88.3)$ & & & \\
\hline 4 & M. malmoense & 7 & 66.9 & 72.3 & 76.2 & $(85.5)$ & & \\
\hline 5 & M. szulgai & 5 & 66.7 & 72.1 & 72.7 & 72.0 & $(85.0)$ & \\
\hline 6 & M. shimoidei & 4 & 57.3 & 64.3 & 69.5 & 73.5 & 65.7 & (86.3) \\
\hline
\end{tabular}

a See Fig. 2.

$b$ The values in parentheses are mean intracluster $M$ scores.

intracellulare marker strain ATCC $13950^{\mathrm{T}}$ at an $M$ score of only $79.3 \%$, and to the other old strain of $M$. intracellulare, strain ATCC 25115, at an $\mathrm{M}$ score of $81.3 \%$. On the other hand, the mean $\mathrm{M}$ score of strain 90002 compared with the strains in the $M$. simiae cluster was $79.5 \%$, although it was linked to $M$. simiae cultures $\mathbf{9 0 0 0 7}$ and 90008 at $\mathrm{M}$ scores of $\mathbf{8 6 . 5}$ and $\mathbf{8 6 . 9 \% \text { , }}$ respectively.

Strains 90034 and 90035 were sputum isolates from two patients who had disease compatible with tuberculosis. The submitter had recorded "brownish" pigmented colonies and high catalase reactions (more than $45 \mathrm{~mm}$ ). By blind retesting of the coded strains the submitter confirmed these properties, but the reports from the other participants were ambiguous. Seven laboratories recorded the strains as nonpigmented, two recorded photochromogenicity, and five reported scotochromogenicity. This tie in terms of presence or absence of pigment resulted in the editing program treating the results as "no data scored" for the presence of pigment and negative for photochromogenicity. In this case, the results were affected by the subjective interpretation of how much pigment was necessary to code a strain as pigmented. The catalase test, on the other hand, does rely on quantitative criteria, but strains 90034 and 90035 were sufficiently variable to lead to ambiguous responses here as well. Thus, 8 of 14 laboratories reported that strain 90035 produced more than $45 \mathrm{~mm}$ of foam, but only 6 of 14 reported this result for strain 90034, so the consensus editing resulted in disagreement between the two strains. There was general agreement that both of these strains belonged to avium complex serovar 7 (Table 4), and they had identical TLC patterns.

The last strain in the MAIS- 1 cluster, strain 90018 , was isolated from the same patient as strains 90016 and 90019 , which appear in the heterogeneous region immediately below the MAIS-1 cluster in Fig. 2. As discussed previously (20), the poor match among these three strains is probably a consequence of the unusually high inter-laboratory variability of the responses to the tests used. None could be placed in any recognized serovar.

Marker strain C (M. avium ATCC 25133) was linked to strain 90039 at an M score of $84.8 \%$, and in turn strain 90039 was linked to strain 90026 at an M score of $81.3 \%$. Both of these new strains appear in the heterogenous region below the MAIS-1 cluster in Fig. 2; neither could be typed to any recognized serovar.

Marker strain D (M. scrofulaceum ATCC 23420) was linked at an M score of only $80 \%$ to a loosely joined group of strains which was comprised predominantly of old strains in the composite dendrogram (Fig. 1). The average linkage dendrogram does not disclose the fact that this marker strain was linked at an M score of $90.6 \%$ to new strain 90043 , which appears in the middle of the $M$. simiae cluster in Fig. 2. However, the $M$. scrofulaceum marker strain exhibited a mean M score compared with the entire new strain $M$. simiae cluster of only $78.9 \%$ (Table 2) and matched only 3 of the other 10 new strains in the cluster at an $\mathrm{M}$ score of more than $80 \%$; strain 90043 had a mean $M$ score of $84.5 \%$ compared with this cluster and matched 8 of the other 10 strains at $\mathrm{M}$ scores of more than $\mathbf{8 0 \%}$ (Fig. 2). Although subtle differences were recorded in different laboratories for the serovar designation of strain 90043 (Table 4), the concensus placed this strain in agreement with other $M$. simiae strains; however, the TLC pattern was not helpful. This strain was photochromogenic, positive for urease and high catalase, and negative for Tween hydrolysis.

Strains 90030 and 90032 , the two new strains in the loosely linked group that included the $M$. scrofulaceum marker strain, had M scores compared with this marker of 84.4 and $74.2 \%$, respectively. Strain 90030 was reported by two laboratories to agglutinate with serovar 42 serum, which is usually associated with $M$. scrofulaceum, but one of these laboratories reported that the absorption test was inconclusive and the other reported that the bacilli also agglutinated 
TABLE 3. Feature frequencies of 34 properties for four clusters of slowly growing mycobacteria ${ }^{a}$

\begin{tabular}{|c|c|c|c|c|c|}
\hline \multirow[b]{2}{*}{ Feature } & \multirow{2}{*}{$\begin{array}{l}\text { RKC } \\
\text { no. }\end{array}$} & \multicolumn{4}{|c|}{ Frequency of features (\%) in the following clusters: } \\
\hline & & MAIS-1 & $\begin{array}{c}M . \\
\text { simiae }\end{array}$ & $\begin{array}{l}M . \\
\text { malmoense }\end{array}$ & $\begin{array}{c}M . \\
\text { szulgai }\end{array}$ \\
\hline \multicolumn{6}{|l|}{ Growth in media containing: } \\
\hline Oleic acid $(0.025 \%)$ & 16089 & $\mathrm{ND}^{r}$ & ND & 0 & ND \\
\hline Picric acid $(0.2 \%)$ & 16259 & 0 & 18 & 0 & 0 \\
\hline Hydroxylamine hydrochloride $(125 \mu \mathrm{g} / \mathrm{ml})$ & 16261 & 100 & 100 & 100 & 80 \\
\hline Hydroxylamine hydrochloride $(500 \mu \mathrm{g} / \mathrm{ml})$ & 16263 & 83 & 100 & 71 & 0 \\
\hline Sodium chloride (5\%) & 18006 & 0 & 0 & 0 & 0 \\
\hline p-Nitrobenzoic acid $(500 \mu \mathrm{g} / \mathrm{ml})$ & 16264 & 100 & 100 & 100 & 100 \\
\hline Isoniazid $(1 \mu \mathrm{g} / \mathrm{ml})$ & 16250 & 100 & 100 & 100 & ND \\
\hline Isoniazid $(10 \mu \mathrm{g} / \mathrm{ml})$ & 16251 & 17 & 70 & 0 & 0 \\
\hline Thiacetazone $(10 \mu \mathrm{g} / \mathrm{ml})$ & 16276 & 100 & 100 & 100 & 100 \\
\hline $\begin{array}{l}\text { Thiophene-2-carboxylic acid hydrazide } \\
(1 \mu \mathrm{g} / \mathrm{ml})\end{array}$ & 16264 & 100 & 100 & 100 & 100 \\
\hline Ethambutol $(5 \mu \mathrm{g} / \mathrm{ml})$ & 16319 & 50 & 100 & 17 & $\mathbf{0}$ \\
\hline Capreomycin $(10 \mu \mathrm{g} / \mathrm{ml})^{d}$ & 40369 & 33 & 100 & 0 & 0 \\
\hline Capreomycin $(71 \mu \mathrm{g} / \mathrm{ml})^{d}$ & 98169 & 33 & 100 & 29 & 0 \\
\hline \multicolumn{6}{|l|}{ Growth characteristics } \\
\hline Growth at $22^{\circ} \mathrm{C}$ & 17036 & 100 & 100 & 86 & 100 \\
\hline Growth at $42^{\circ} \mathrm{C}$ & 17035 & 0 & 9 & 0 & 0 \\
\hline Glucose used as sole carbon source & 25311 & $\mathbf{0}$ & 55 & 0 & 20 \\
\hline 1-Propanol used as sole carbon source & 26524 & $\mathbf{0}$ & 91 & 0 & 0 \\
\hline Glutamate used as sole $\mathrm{N}$ and $\mathrm{C}$ sources & 29227 & 0 & $\mathbf{0}$ & $\mathbf{0}$ & 0 \\
\hline $\begin{array}{l}\text { Acetate used as sole } \mathrm{C} \text { source, glutamate } \\
\text { used as sole } \mathrm{N} \text { source }\end{array}$ & 98091 & 100 & 100 & 29 & 80 \\
\hline $\begin{array}{l}\text { Succinate used as sole } \mathrm{C} \text { source, } \\
\text { glutamate used as sole } \mathrm{N} \text { source }\end{array}$ & 98092 & 33 & 55 & $\mathbf{0}$ & 0 \\
\hline Photochromogenic & 20008 & $\mathbf{0}$ & 90 & $\mathbf{0}$ & $\mathbf{0}$ \\
\hline Pigment produced & 20018 & 0 & 90 & $\mathbf{0}$ & 100 \\
\hline Niacin accumulated & 24424 & $\mathbf{0}$ & 46 & 0 & 0 \\
\hline \multicolumn{6}{|l|}{ Enzymatic properties } \\
\hline Urease & 34143 & $\mathbf{0}$ & 100 & 71 & 80 \\
\hline Nicotinamidase & 30255 & 83 & 46 & 100 & 80 \\
\hline Pyrazinamidase & 30258 & 83 & 30 & 100 & 80 \\
\hline$\alpha$-Esterase & 34146 & 100 & 89 & 67 & 75 \\
\hline Acid phosphatase & 34136 & 80 & 0 & 0 & 100 \\
\hline B-Galactosidase & 34123 & 0 & 0 & 0 & 0 \\
\hline Catalase, $>45 \mathrm{~mm}$ of foam & 98009 & 100 & 100 & $\mathbf{0}$ & 100 \\
\hline Catalase resists $68^{\circ} \mathrm{C}, 20 \mathrm{~min}$ & 24425 & 100 & 100 & ND & 100 \\
\hline Nitrate reduction & 98007 & 0 & 0 & 0 & 100 \\
\hline Tween $\mathbf{8 0}$ hydrolysis within $\mathbf{1 0}$ days & 98030 & 17 & 0 & 100 & 80 \\
\hline Arylsulfatase within 14 days & 98002 & 100 & 46 & 57 & 100 \\
\hline
\end{tabular}

a The data are based on new strains only, and only newly recognized clusters or clusters to which additional strains were added since the previous report (20) are described. Entries are based on data for at least four strains per cluster; seven features included in the previous report were excluded because they were based on fewer than four new strains, the balance having been derived from old strains. See text for definitions of old and new strains.

$b$ The RKC numbers refer to the code numbers for the features contained in the data file (8).

c ND, Not enough data for tabulation.

d The RKC method (8) codes for susceptibility to capreomycin; therefore, the computer output data were inverted for this table, which records as percent resistant. Data are from two different laboratories.

with an antiserum to Mycobacterium chelonei. The TLC pattern was not like any of the reference patterns. This strain was linked to no strain in the $M$. simiae cluster at an $M$ score of more than $78.4 \%$ and to only one strain at an $M$ score of more than $75 \%$. Strain 90032 was an avium serovar 6 strain and had an $M$ score of $\mathbf{8 2 . 8 \%}$ compared with marker strain B $(M$. intracellulare ATCC $13950^{\mathrm{T}}$ ). The concensus description of strains 90030 and 90032 was that they are scotochromogenic, negative for Tween 80 hydrolysis and for urease, and positive for high catalase (more than $\mathbf{4 5} \mathrm{mm}$ of foam). Thus, both of these strains met the criteria of Hawkins (3) for MAIS intermediate status.

Marker strain E ("M. paraffinicum" ATCC 12670) clustered with four other old strains in the composite dendrogram (Fig. 1), with a mean 
TABLE 4. Distribution of agglutinating serovars and TLC patterns of lipid extracts of new strains according to NT clustering behavior

\begin{tabular}{|c|c|c|c|c|c|c|}
\hline \multirow{3}{*}{ Cluster } & \multirow{3}{*}{ Strain } & \multicolumn{5}{|c|}{ Results by laboratories ${ }^{a}$} \\
\hline & & \multirow{2}{*}{$\begin{array}{c}\text { TLC } \\
\text { (laboratory 1) }\end{array}$} & \multicolumn{4}{|c|}{ Agglutinating serovar } \\
\hline & & & Laboratory 9 & Laboratory 10 & Laboratory 13 & Laboratory 20 \\
\hline \multirow[t]{10}{*}{ M. simiae } & 90025 & NSL & 18 & (N) & 18 & 18 \\
\hline & 90010 & PNH & 18 & 18 & 18 & $18 B$ \\
\hline & 90021 & PNH & 18 & 18 & 18 & $18 B$ \\
\hline & 90009 & PNH & 18 & 18 & 18 & 18 \\
\hline & 90012 & PNH & simiae 1 & simiae 1 & $(\mathbf{N})$ & simiae 1 \\
\hline & 90043 & PNH & 18 & (N) & 18 & simiae 142 \\
\hline & 90006 & PNH & simiae 2(?) & 18 & 18 & (N) \\
\hline & 90024 & intracellulare & simiae 2(?) & & 18 & simiae 2 \\
\hline & $\begin{array}{l}90008 \\
90007\end{array}$ & & $\begin{array}{c}\text { simiae } 1(?) \\
18\end{array}$ & $\begin{array}{r}\operatorname{simiae} 1 \\
(\mathbf{N})\end{array}$ & $\begin{array}{c}(\mathrm{N}) \\
18\end{array}$ & $\begin{array}{c}\text { simiae } 1 \mathrm{~B}, 2 \mathrm{~A} \\
18\end{array}$ \\
\hline & 90022 & & simiae $2(?)$ & simiae 2 & 18 & simiae 2 \\
\hline \multirow[t]{4}{*}{ M. asiaticum } & 90028 & NSL & & (R) & $(\mathbf{N})$ & (N) \\
\hline & 90041 & gordonae & $(\mathbf{N})$ & (R) & (N) & gordonae IIIB \\
\hline & 90052 & malmoense? & (R) & & (N) & (N) \\
\hline & 90053 & malmoense? & (N) & & (N) & (N) \\
\hline \multirow[t]{6}{*}{ MAIS-1 } & 90004 & & 25 & 25 & (R) & 25 \\
\hline & 90002 & & 18 & 18 & 18 & $18 B$ \\
\hline & 90023 & NSL & 25 & 22 & $(\mathbf{N})$ & 25 \\
\hline & 90035 & PNH $^{b}$ & $7(?)$ & 7 & 7 & 7 \\
\hline & 90034 & PNH $^{b}$ & $7 / 22(?)$ & 7 & 7 & 7 \\
\hline & 90018 & & $(\mathbf{N})$ & (N) & (N) & $(\mathrm{N})$ \\
\hline \multirow[t]{7}{*}{ M. malmoense } & 90047 & malmoense & (R) & (N) & (N) & malmoense \\
\hline & 90048 & malmoense & (R) & (N) & (N) & malmoense \\
\hline & 90045 & malmoense & (R) & (R) & (N) & malmoense \\
\hline & 90044 & malmoense & (R) & (R) & (N) & malmoense \\
\hline & 90049 & malmoense & (R) & (R) & (N) & malmoense \\
\hline & 90051 & malmoense & (R) & & (N) & $(\mathbf{N})$ \\
\hline & 90050 & malmoense? & (R) & & (N) & (N) \\
\hline \multirow[t]{5}{*}{ M. szulgai } & 90036 & PNH & (R) & gastri(?) & Baxter & (R) \\
\hline & 90020 & szulgai & szulgai & szulgai & Baxter & (N) \\
\hline & 90001 & szulgai & szulgai & szulgai & Baxter & $24 B$ \\
\hline & 90011 & szulgai & (R) & (N) & (R) & (R) \\
\hline & 90046 & NSL & (R) & (N) & (R) & szulgai \\
\hline \multirow[t]{4}{*}{ M. shimoidei } & 90014 & NSL & (R) & (R) & (R) & $(\mathrm{N})$ \\
\hline & 90015 & NSL & (R) & (R) & (R) & (N) \\
\hline & 90013 & & (R) & (R) & (R) & (N) \\
\hline & 90027 & & (R) & (R) & (R) & (R) \\
\hline \multirow[t]{3}{*}{ Unclustered $^{c}$} & 90030 & PNH & 42(?) & 42/chelonei(?) & (N) & scrofulaceum(?) \\
\hline & 90032 & & (R) & 6 & 6 & 6 \\
\hline & 90016 & PNH & (R) & (R) & & (R) \\
\hline
\end{tabular}

a Numbers without any other designation represent avium complex serovars, according to the scheme of Wolinsky and Schaefer (22). Abbreviations: (N), not typable because the cells did not agglutinate with any of the reference sera available in the laboratory; (?), specificity of agglutination could not be confirmed by absorption; (R), rough (spontaneous agglutination); NSL, no specific lipids observed; PNH, pattern not helpful.

b Strains 90034 and 90035 produced the same TLC pattern.

c Unclustered strains $90037,90029,90042,90019,90039,90026,90040,90031$, and 90033 either were not typable or were rough (spontaneous agglutination).

$M$ score of $90.8 \%$ compared with the other four strains. Since it embraced no new strains, a cluster corresponding to " $M$. paraffinicum" does not appear in the restricted NT triangle (Fig. 2). "M. paraffinicum"' (1) is without standing, although we suggested previously (20) that this name might ultimately be revived; the present data indicate that revival at this time would be premature. Marker strain $\mathbf{E}$ exhibited $\mathbf{M}$ scores of more than $85 \%$ compared with eight new strains; one of these (strain 90023) occurs in the MAIS-1 cluster, one (strain 90026) is isolated, five (strains 90043, 90025, 90010, 90021, and 90009) appear in the $M$. simiae cluster, and one (strain $\mathbf{9 0 0 2 8}$ ) appears in the $M$. asiaticum cluster of Fig. 2. 
Marker strain F (Mycobacterium gordonae ATCC 23409) exhibited an M score of $87.1 \%$ compared with strain 90052 , which appeared in the loose $M$. asiaticum cluster, but an M score of $80 \%$ or less compared with any other new strain.

Marker strain G (M. simiae ATCC 25275 ${ }^{\mathrm{T}}$ ) (4) appeared in a cluster of three old strains and seven new strains in the previous study (20). In the present analysis, strains 90006 and 90022 , two new strains that appeared to be isolated in the previous study, joined the $M$. simiae cluster, albeit at low mean levels of linkage to the other new strains (M scores of 79.5 and $78.0 \%$, respectively). Strains 90024 and 90043 , two other strains that were introduced into the study since the previous report, joined the $M$. simiae cluster (mean M scores compared with the other new strains, 80.8 and $84.5 \%$, respectively). The net result of deletion of old strains and introduction of additional new strains to the $M$. simiae cluster of Fig. 2 was a gain of one strain. This resulted in only minor changes in the percent feature frequencies presented in Table 3 and no change in the overall modal description from that presented in the previous report (20). The mean internal M score of the whole cluster was $83.1 \%$ (Table 2). $M$. simiae appears to be comprised of a tight subcluster (mean internal M score, $88.9 \%$ ) of six strains (strains 90025 through 90043 in Fig. 2), all but one of which agglutinated as serovar 18 strains, and a looser subcluster (mean internal $\mathrm{M}$ score, $85.4 \%$ ) of strains (strains 90024 to 90022 in Fig. 2), with a more varied set of serovar reports. Strain 90006 is linked poorly to both subclusters, but appears to be related in terms of serovar.

Of the features of the $M$. simiae cluster that appeared to be most variable in Table 3, most of the discrepancies were distributed inconsistently between the two subclusters. However, the results of the niacin test showed notable correlation with agglutination serovar. Of the six tightly linked strains at the top of the $M$. simiae cluster (Fig. 2), five were serovar 18 strains, and these strains yielded negative concensus results among the 15 laboratories that performed the niacin test; only strain 90012, which was a serovar simiae 1 strain, was positive for niacin (inter-laboratory agreement, 87\%). Conversely, strain 90007, which was in the lower, loosely linked subcluster of five strains, was consistently reported as agglutinating as serovar 18 , and it was the only strain among the five that was reported by the majority of laboratories (interlaboratory agreement, $58 \%$ ) as negative in the niacin test. The overall agreement among laboratories that reported the niacin test with concensus results for each strain in the $M$. simiae cluster was $82.9 \%$.
Marker strain $\mathrm{H}$ (M. asiaticum ATCC $25276^{\mathrm{T}}$ ) (21) exhibited mean linkage to the four new strains in the $M$. asiaticum cluster of $86.3 \%$ (M score), but the mean internal $M$ score of these four strains was only $79.2 \%$. Strain 90052 showed an $\mathrm{M}$ score of $\mathbf{8 8 . 2 \%}$ compared with marker strain $\mathrm{H}$, but a mean $\mathrm{M}$ score of only $79.5 \%$ compared with its own cluster; this strain showed a lipid TLC pattern suggestive of $M$. malmoense, as did strain 90053 , which matched strain 90052 at an $\mathrm{M}$ score of $84.6 \%$. Strain 90041, which agglutinated as an $M$. gordonae serovar in one laboratory and had a lipid TLC pattern like that of $M$. gordonae (Table 4), matched marker strain $\mathrm{H}$ at an $\mathrm{M}$ score of $84.8 \%$ and marker strain $\mathrm{F}$ at an $\mathrm{M}$ score of $80.0 \%$. The $M$. asiaticum cluster is presently too poorly defined to justify inclusion of its feature frequency data in Fig. 3.

$M$. malmoense appeared to be a homogeneous cluster (mean internal $\mathrm{M}$ score, $85.5 \%$ ) that was comprised almost entirely of new strains and was linked to no marker strain or other cluster at an $\mathrm{M}$ score of more than $73.5 \%$ (Tables 1 and 2). Superficially, in terms of the more commonly used diagnostic tests, $M$. malmoense resembled $M$. gastri and $M$. nonchromogenicum, but none of the members of this cluster matched marker strain $\mathrm{J}$ or $\mathrm{N}$ at an $\mathrm{M}$ score of more than $70 \%$, and a distinctive serovar and lipid TLC pattern was reported for most strains of $M$. malmoense. Consistently negative phosphatase and positive pyrazinamidase reactions are among the most powerful biochemical features (Table 3) that distinguish $M$. malmoense from $M$. gastri. Negative reactions for high catalase, acid phosphatase, and $\beta$-galactosidase distinguish $M$. malmoense from $M$. nonchromogenicum. These distinctions are important, since $M$. malmoense is considered pathogenic (10), whereas $M$. gastri and $M$. nonchromogenicum are not.

Marker strain L (Mycobacterium flavescens ATCC $14474^{\mathrm{T}}$ ) had a mean $M$ score of $78.0 \%$ compared with the five new strains in the $M$. szulgai cluster and an M score of less than $70 \%$ compared with any other cluster. As discussed previously (20), this strain should probably be considered one of the rapidly growing species of Mycobacterium, which were exluded from this study.

M. szulgai (6) appeared as a cluster of one old and three new strains in the previous study (20). Two recently introduced strains (strains 90036 and 90046) have since joined this cluster, providing a net gain of one strain after exclusion of the old strain. This cluster resembles no marker strain or other cluster at an $\mathrm{M}$ score of more than 78.9\% (Tables 1 and 2) and has a mean internal $\mathrm{M}$ score of $85.0 \%$. As discussed previously (20), this species is most easily confused with $M$. 
flavescens when the most commonly used diagnostic tests are used, but its susceptibility to $0.2 \%$ picric acid and $5 \% \mathrm{NaCl}$ and resistance to hydroxylamine hydrochloride $(125 \mu \mathrm{g} / \mathrm{ml})$ distinguish it from the latter species. Four of the strains were identified in at least one laboratory as belonging to an $M$. szulgai or "Baxter" serovar, and the fifth strain was described as having the "szulgai" type of lipid TLC pattern, even though it could not be typed by agglutination tests. The Baxter antisera had been prepared in laboratory 13 against two strains identified as $M$. intracellulare, so further studies will be needed to confirm whether the Baxter antigen from $M$. intracellulare is identical to the antigen from $M$. szulgai.

$M$. shimoidei appeared as a cluster of four new strains which had a mean internal $\mathbf{M}$ score of 86.3\%. This species lost standing when the Approved Lists of Bacterial Names were published (11), but has since been revived (13). This cluster was described and discussed in our previous report (20), and no additional strains have joined the cluster.

\section{DISCUSSION}

The decision to delete old strains in our detailed analysis of clusters (Fig. 2) resulted in the loss of three and one strains of $M$. simiae and $M$. szulgai, respectively. These losses were compensated for by the introduction of four and two additional new strains to these clusters. These changes had only minimal effects on the percent feature frequencies for these species (Table 3) and no effect on the species modal patterns. The invalid species " $M$. paraffinicum" was lost completely, since no new strains in the study were linked to the old marker strain at a level that moved them out of some other cluster. The $M$. asiaticum cluster was so poorly defined that it resisted adequate description. It is clearly important to have marker strains available for future analysis, as well as to characterize the old strains that were deleted. Fortunately, we have been able to recover most of the actual cultures corresponding to the old strains, and these cultures will be recoded and distributed as unknowns so they can reenter the data base for analyses at a later date. We anticipate that after reentry of these strains, a clearer picture will emerge as to the advisability of reviving " $M$. paraffinicum" and of continuing to support the recognition of $M$. asiaticum as a species.

Among the strains in this series that met the criteria of Hawkins (3) for MAIS intermediate status, many could be accounted for by cultures of $M$. simiae in which photochromogenicity was not detected. Problems of reproducibility of pigment detection in this species have been discussed previously (20). On the other hand, some strains that were originally submitted as possible MAIS intermediates appear in a separate cluster, designated MAIS-1 (Fig. 2), but these strains may represent minor variants of $M$. intracellulare. There is presently no convincing evidence for erecting a new species to accommodate them.

Two new strains, strains 90030 and $\mathbf{9 0 0 3 2}$, fell into a loose group in the composite dendrogram (Fig. 1) with some affinity for the $M$. scrofulaceum marker strain and may indeed provide a basis for another MAIS intermediate cluster when cultures of old strains have been distributed and reenter the study.

Although the $M$. simiae cluster (Fig. 2) consists of a tight subcluster and a looser subcluster, the only consistent differences observed between these two subclusters were in seroagglutination and the niacin test. At present this does not appear to be a sufficient reason to justify establishment of subspecies of $M$. simiae, and simple designation of serovars, and possibly chemovars, should be sufficient.

Even after the deletion of old strains, the $\boldsymbol{M}$. szulgai cluster (Fig. 2) was expanded compared with this cluster in our previous report (20). Table 3 shows feature frequencies other than 0 or $100 \%$ for only eight of the key features presented. For each of these eight key features, the discrepancies from the modal pattern occurred in single strains. Strain 90046 accounted for 5 of the discrepancies, strain 90036 accounted for 2, and strain 90001 accounted for the remaining discrepancy. Even on the composite dendrogram (Fig. 1) which included old strains, strain 90046 showed poor linkage to any cluster, and its relationship to $M$. szulgai is open to question. Only one laboratory recorded this strain as a member of the $M$. szulgai serovar, and the TLC pattern, which represented one of the original bases for establishing this species (6), was not characteristics.

A very discrete cluster corresponding to $M$. malmoense (10) did not appear in our previous report (20); all of the new strains in this cluster entered the study after the first analysis. Only one old strain, strain ATCC 15983, joined this cluster in the composite dendrogram (Fig. 1); this strain had shown some affinity (M score, more than $80 \%$ ) to strains 90016 and 90018 in the previous study (20), but the latter two strains did not join the $\boldsymbol{M}$. malmoense cluster in the present analysis.

TLC of mycobacterial lipids appears to be of limited value in this type of study. Species with very distinct lipid patterns, such as $M$. malmoense and $M$. szulgai, are readily identified, but in most other cases there is either a pattern which it is difficult to link with other patterns that have been observed before or there is an 
absence of specific lipids. It might be more profitable to examine the clusters once they have been established by NT. This could confirm the homogeneity of a cluster and might also indicate variants within it.

\section{ACKNOWLEDGMENTS}

This study was supported in part by the Medical Research Service of the Veterans Administration.

The excellent assistance of Linda Skutt in transcribing data submitted by participants for computer analysis is gratefully acknowledged.

\section{LITERATURE CITED}

1. Davis, J. B., H. H. Chase, and R. L. Raymond. 1956. Mycobacterium paraffinicum $\mathrm{n}$. sp., a bacterium isolated from soil. Appl. Microbiol. 4:310-315.

2. Goodfellow, M., A. Lind, H. Mordarska, S. Pattyn, and M. Tsukamura. 1974. A co-operative numerical analysis of cultures considered to belong to the rhodochrous taxon. J. Gen. Microbiol. 85:291-302.

3. Hawkins, J. 1977. Scotochromogenic mycobacteria which appear intermediate between $M$. avium/intracellulare and M. scrofulaceum. Am. Rev. Respir. Dis. 116:963-964.

4. Karasseva, V., J. Weiszfeller, and E. Krasnay. 1965. Occurrence of atypical mycobacteria in Macacus rhesus. Acta Microbiol. Acad. Sci. Hung. 12:275-282.

5. Kubica, H. P., I. Baess, R. E. Gordon, P. A. Jenkins, J. B. G. Kwapinski, C. McDurmont, S. R. Pattyn, H. Saito, V. Silcox, J. L. Stanford, K. Takeya, and M. Tsukamura. 1972. A co-operative numerical analysis of rapidly growing mycobacteria. J. Gen. Microbiol. 73:55-70.

6. Marks, J., P. A. Jenkins, and M. Tsukamura. 1972. Mycobacterium szulgai-a new pathogen. Tubercle 53:210-214.

7. Meissner, G., K. H. Schröder, H. E. Amadio, W. Anz, S. Chaparas, H. W. B. Engel, P. A. Jenkins, W. Käppler, H. H. Kleeberg, E. Kubala, M. Kubin, D. Lauterbach, A. Lind, M. Magnusson, Zd. Mikova, S. R. Pattyn, W. B. Schaefer, J. L. Stanford, M. Tsukamura, L. G. Wayne, I. Willers, and E. Wolinsky. 1974. A cooperative numerical analysis of nonscoto- and nonphotochromogenic slowly growing mycobacteria. J. Gen. Microbiol. 83:207-235.

8. Rogosa, M., M. I. Krichevsky, and R. R. Colwell. 1971. Method for coding data on microbial strains for computers (edition AB). Int. J. Syst. Bacteriol. 21:1A-175A.

9. Saito, H., R. E. Gordon, I. Juhlin, W. Käppler, J. B. G. Kwapinski, C. McDurmont, S. R. Pattyn, E. H. Runyon, J. L. Stanford, S. Tarnok, H. Tasaka, M. Tsukamura, and J. W. Weiszfeiler. 1977. Cooperative numerical analysis of rapidly growing mycobacteria. Int. J. Syst. Bacteriol. 27:75-85.

10. Schröder, K. H., and I. Juhlin. 1977. Mycobacterium malmoense sp. nov. Int. J. Syst. Bacteriol. 27:241-246.

11. Skerman, V. B. D., V. McGowan, and P. H. A. Sneath (ed.). 1980. Approved lists of bacterial names. Int. J. Syst. Bacteriol. 30:225-420.

12. Sneath, P. H. A., and R. R. Sokal. 1973. Numerical taxonomy. W. H. Freeman and Co., San Francisco.
13. Tsukamura, M. 1982. Mycobacterium shimoidei sp. nov., nom. rev., a lung pathogen. Int. J. Syst. Bacteriol. 32:6769.

14. Walczak, C. A., and M. I. Krichevsky. 1980. Computer methods for describing groups from binary phenetic data: preliminary summary and editing of data. Int. J. Syst. Bacteriol. 30:615-621.

15. Walczak, C. A., and M. I. Krichevsky. 1980. Computer methods for describing groups from binary phenetic data: modification of numerical taxonomy programs to increase flexibility. Int. J. Syst. Bacteriol. 30:622-626.

16. Wayne, L. G., L. Andrade, S. Froman, W. Käppler, E. Kubala, G. Meissner, and M. Tsukamura. 1978. A cooperative numerical analysis of Mycobacterium gastri, Mycobacterium kansasii and Mycobacterium marinum. J. Gen. Microbiol. 109:319-327.

17. Wayne, L. G., T. M. Dietz, C. Gernez-Rieux, P. A. Jenkins, W. Käppler, G. P. Kubica, J. B. G. Kwapinski, G. Meissner, S. R. Pattyn, E. H. Runyon, K. H. Schröder, V. A. Silcox, A. Tacquet, M. Tsuksmura, and E. Wolinsky. 1971. A cooperative numerical analysis of scotochromogenic slowly growing mycobacteria. J. Gen. Microbiol. 66:255-271.

18. Wayne, L. G., H. C. Engbaek, H. W. B. Engel, S. Froman, W. Gross, J. Hawkins, W. Käppler, A. G. Karlson, H. H. Kleeberg, I. Krasnow, G. P. Kubica, C. McDurmont, E. E. Nel, S. R. Pattyn, K. H. Schröder, S. Showalter, I. Tarnok, M. Tsukamura, B. Vergman, and E. Wolinsky. 1974. Highly reproducible techniques for use in systematic bacteriology of the genus Mycobacterium: tests for pigment, urease, resistance to sodium chloride, hydrolysis of Tween 80, and $\beta$-galactosidase. Int. J. Syst. Bacteriol. 24:412-419.

19. Wayne, L. G., H. W. B. Engel, C. Grassi, W. Gross, J. Hawkins, P. A. Jenkins, W. Käppler, H. H. Kleeberg, I. Krasnow, E. E. Nel, S. R. Pattyn, P. A. Richards, S. Showalter, M. Slosarek, I. Szabo, I. Tarnok, M. Tsukamura, B. Vergmann, and E. Wolinsky. 1976. Highly reproducible techniques for use in systematic bacteriology in the genus Mycobacterium: tests for niacin and catalase and for resistance to isoniazid, thiophene 2carboxylic acid, hydrazide, hydroxylamine, and $p$-nitrobenzoate. Int. J. Syst. Bacteriol. 26:311-318.

20. Wayne, L. G., R. C. Good, M. I. Krichevsky, R. E. Beam, Z. Blacklock, S. D. Chaparas, D. Dawson, S. Froman, W. Gross, J. Hawkins, P. A. Jenkins, I. Juhlin, W. Kăppler, H. H. Kleeberg, I. Krasnow, M. J. Lefford, E. Mankiewicz, C. McDurmont, G. Meissner, P. Morgan, E. E. Nel, S. R. Pattyn, F. Portaels, P. A. Richards, S. Rusch, K. H. Schröder, V. A. Silcox, I. Szabo, M. Tsukamura, and B. Vergmann. 1981. First report of the cooperative, open-ended study of slowly growing mycobacteria by the International Working Group on Mycobacterial Taxonomy. Int. J. Syst. Bacteriol. 31:1-20.

21. Weiszfeiler, G., V. Karasseva, and E. Karczag. 1971. A new Mycobacterium species: Mycobacterium asiaticum n. sp. Acta Microbiol. Acad. Sci. Hung. 18:247-252.

22. Wolinsky, E., and W. B. Schaefer. 1973. Proposed numbering scheme for mycobacterial serotypes by agglutination. Int. J. Syst. Bacteriol. 23:182-183. 